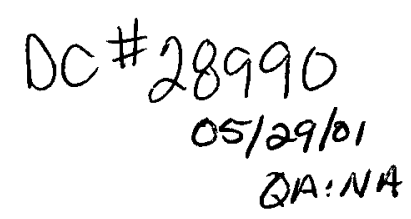

\title{
Yellowstone as an analog for thermal-hydrological-chemical processes at Yucca
}

\section{Mountain}

Patrick F. Dobson, Timothy J. Kneafsey, Ardyth Simmons, and Jeffrey Hulen ${ }^{1}$

MOL. 20010827.0044

${ }^{1}$ Energy and Geoscience Institute, University of Utah

Contact: Patrick F. Dobson, 510/ 486-5373, pfdobson@lbl.gov

\section{Research Objectives}

Enhanced water-rock interaction resulting from the emplacement of heat-generating nuclear waste in the potential geologic repository at Yucca Mountain, Nevada, may result in changes to fluid flow (resulting from mineral dissolution and precipitation in condensation and boiling zones, respectively). Studies of water-rock interaction in active and fossil geothermal systems (natural analogs) provide evidence for changes in permeability and porosity resulting from thermal-hydrological-chemical (THC) processes. The objective of this research is to document the effects of coupled THC processes at Yellowstone and then examine how differences in scale could influence the impact that these processes may have on the Yucca Mountain system.

\section{Approach}

Subsurface samples from Yellowstone National Park, one of the largest active geothermal systems in the world, contain some the best examples of hydrothermal self-sealing found in geothermal systems (Figure 1). We selected core samples from two USGS research drill holes from the transition zone between conductive and convective portions of the geothermal system (where sealing was reported to occur). We analyzed the core, measuring the permeability, porosity, and grain density of selected samples to evaluate how lithology, texture, and degree of hydrothermal alteration influence matrix and fracture permeability.

\section{Accomplishments}

We examined core samples from the Y-5 and Y-8 drill holes, describing lithology, texture, hydrothermal alteration, and veins and fractures. Observed variations in porosity and matrix permeability are primarily controlled by lithology. Volcaniclastic sandstone and nonwelded tuffs have high porosity and moderate matrix permeability, while densely welded ash-flow tuffs and rhyolite lavas have low porosity and permeability. Fractures are most abundant in the latter two lithologies, and provide the dominant pathways for fluid flow there. Most of the observed fractures have been sealed by hydrothermal mineralization. A zone of secondary silica mineralization in the Y-8 core corresponds to the location of the impermeable cap for the near-isothermal, convective geothermal reservoir.

\section{Significance of Findings}

Predicting changes in permeability and porosity resulting from water-rock interaction is important in the evaluation of long-term performance of nuclear waste repositories and for geothermal reservoir engineering. Geothermal systems have much higher fluxes of heat and fluid flow than those predicted for the potential Yucca Mountain repository, and thus the extent of hydrothermal mineralization (and resulting permeability and porosity 


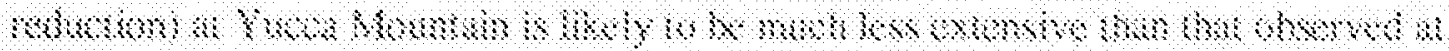

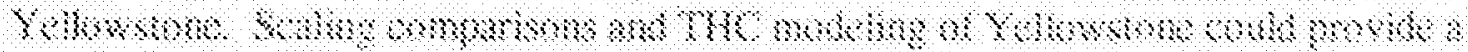

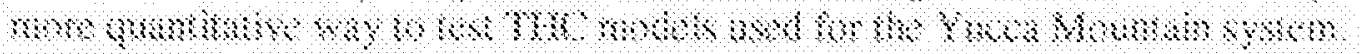

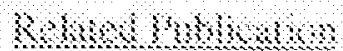

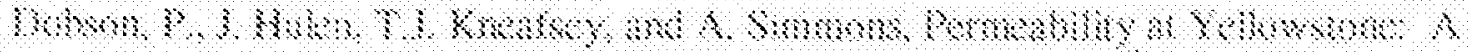

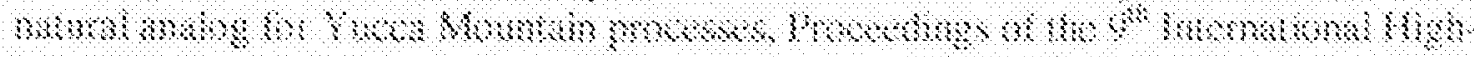

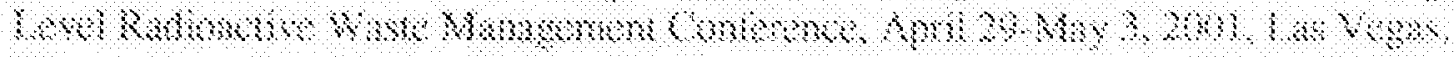

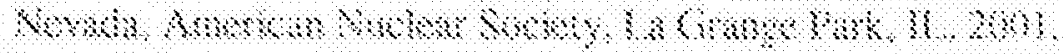

\section{$\mathrm{B} \times \mathrm{M} \leftrightarrow \mathrm{s} \times \mathrm{M}$}

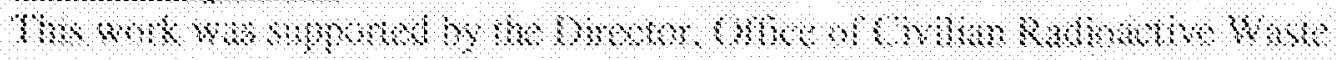

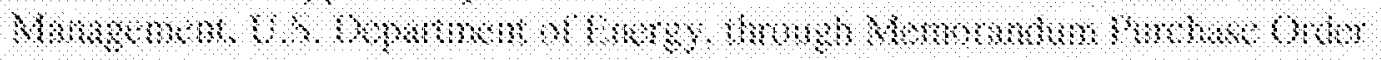

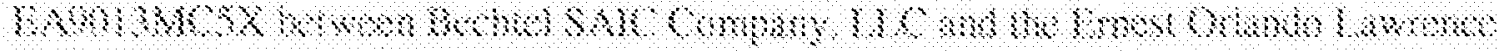

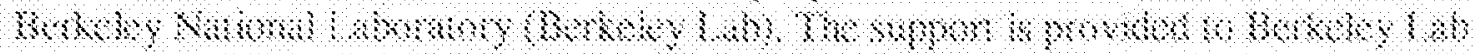

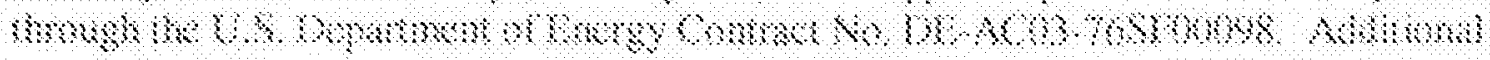

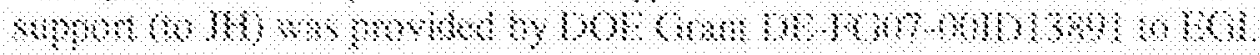

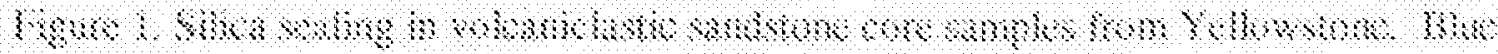

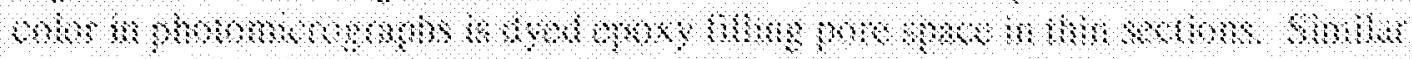

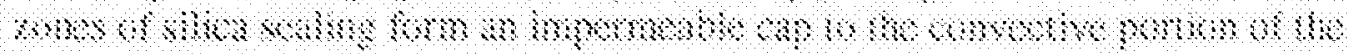

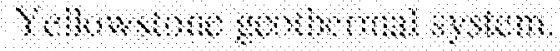

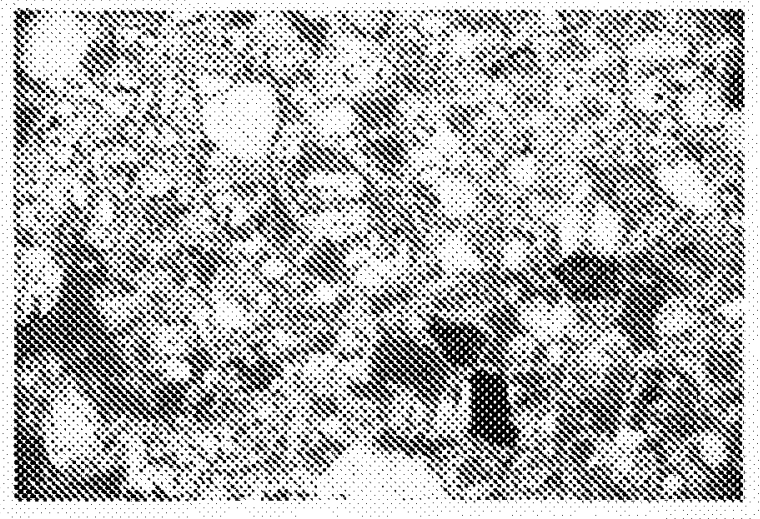

$8 \times, 1,4$,

bomantas $=1930 \mathrm{mb}$

$00 \mathrm{sis}=2$.

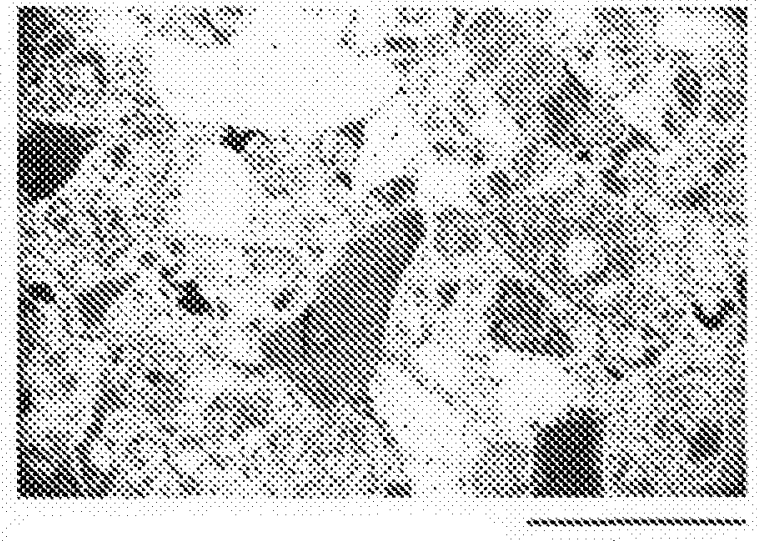

$\times, \$ \diamond, 2$

Pomenmbr $\& \$ 6,9 \mathrm{~m}$

Brsxy $\approx 140$ 